\section{LAST FEW DAYS FOR ADAM NOMINATIONS!}

As this issue of BDJ Team is published online, there are just THREE DAYS left to enter the ADAM Awards 2014.

The Association of Dental Administrators and Managers (ADAM) invites entries for Practice Manager of the Year, Administrator of the Year and Treatment Co-ordinator of the Year, by the extended deadline of 30 June 2014. The winner in each category will receive a cheque for $£ 500$.

The ADAM Awards, sponsored by Denplan, are presented to individuals within the dental practice administration team who demonstrate commitment to their ever-changing roles. The 2013 winners were Lisa Parker, Karen Wheeler and Clare Maidlow.

Individuals may only enter one award category, and the entry form includes completing a personal statement on what singles your practice out from the competition in no more than 750 words. For more details and to download the form, visit http://adam-aspire. co.uk/news-and-events/34-news-andevents/212-adam-awards-2014.
DINOSAUR DOUGLAS AND THE BEASTLY BUGS.

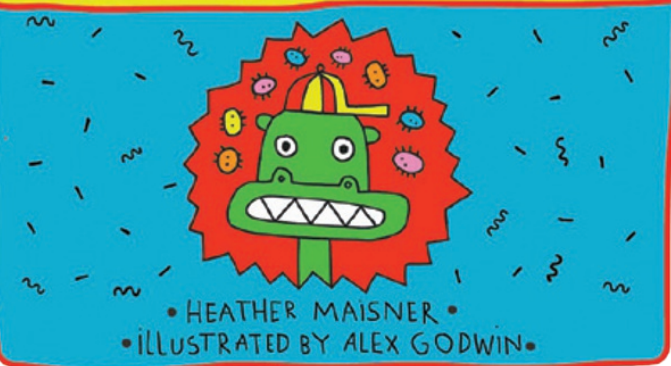

DINOSAUR DOUGLAS TACKLES DENTAL CARIES

Hammersmith \& Fulham Council in London have sponsored the publication of Dinosaur Douglas and the beastly bugs to help drive down the rate of dental caries in young people.

Dinosaur Douglas is an 'expert toothbrusher with a bright white smile', created by children's author Heather Maisner. The book weaves evidence-based messages about diet and toothbrushing into an engaging, rhyming story with colourful illustrations. Its publication coincided with the British Dental Health

Foundation's National Smile 2014.

Three thousand copies of Heather's book have been given out to children in nursery and reception classes across Hammersmith and Fulham along with a toothbrush and toothpaste, and copies have also been given to local libraries and children's centres.

Twenty-eight percent of five-year-olds in Hammersmith and Fulham have decayed, missing or filled teeth, and tooth decay is the top cause for child hospital admissions in the area.

The book was launched on 'Healthy Teeth Day', 11 June, at Melcombe Children's Centre in Hammersmith. At the event, oral health experts from Central London Community Healthcare NHS Trust demonstrated mouth care techniques to parents and children and explained the importance of good brushing and other bedtime routines, such as reading to children. www.nhs.uk/livewell/dentalhealth

Did your dental practice get involved with National Smile Month? Email bdjteam@nature.com
Infection Prevention 2014 will be held in the SECC Glasgow from 29 September to 1 October, offering delegates the latest in infection prevention research, education and expertise. To view the programme visit www. ips.uk.net and click on the conference icon on the homepage.
Do you have a news story that you would like included in BDJ Team? Send your press release or a summary of your story to the Editor at bdjteam@nature.com.

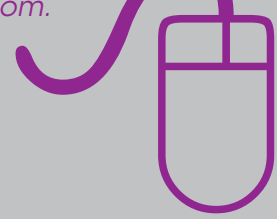

